This PDF is a selection from a published volume from the National Bureau of Economic Research

Volume Title: International Differences in Entrepreneurship

Volume Author/Editor: Josh Lerner and Antoinette Schoar, editors

Volume Publisher: University of Chicago Press

Volume ISBN: 0-226-47309-0; 978-0-226-47309-3

Volume URL: http://www.nber.org/books/lern08-2

Conference Date: February 1-2, 2008

Publication Date: May 2010

Chapter Title: Are there Cultural Determinants of Entrepreneurship?

Chapter Author: Rajkamal Iyer, Antoinette Schoar

Chapter URL: http://www.nber.org/chapters/c8219

Chapter pages in book: (209 - 240) 


\title{
Are There Cultural Determinants of Entrepreneurship?
}

\author{
Rajkamal Iyer and Antoinette Schoar
}

\subsection{Introduction}

Entrepreneurs are at the heart of economic activity and growth. Economic theories from Schumpeter to Baumol have highlighted entrepreneurship as the driving force for change and innovation in a capitalist system. Schumpeter's famous theory of "creative destruction" postulates that the entry of entrepreneurial firms overturns obsolete and inefficient firms and replaces them with innovative technologies. An alternative channel is highlighted by Baumol (2002). Here the innovative behavior of new firms is seen not as a way to force out existing companies but to infuse the economy with innovations and R\&D that can be levered across all firms.

However, while most economists agree that entrepreneurs are central to the functioning of the economy, entrepreneurs have proven quite elusive as an object of empirical study. Some of the most fundamental questions about entrepreneurship go curiously unaddressed in economics. For example, where do entrepreneurs come from and what makes good entrepreneurs? Some of this gap in research might be explained by the complexity of the measurement issues in addressing these questions and the fact that entrepreneurial activities by their very nature have large idiosyncratic components

Rajkamal Iyer is an assistant professor at Amsterdam Business School, University of Amsterdam. Antoinette Schoar is the Michael Koerner '49 Professor of Entrepreneurial Finance at the Massachusetts Institute of Technology Sloan School of Management and codirector of the Entrepreneurship Group at the National Bureau of Economic Research.

We thank Bade Kucukoglu, Janina Matuszeski, and especially Sandhya Kumar for outstanding research assistance. We thank Sendhil Mullainathan, Morten Sorenson, Chris Woodruff, and seminar participants at the NBER pre-conference on International Differences in Entrepreneurship for many helpful comments. The Institute for Financial Markets Research in Chennai, India and the Institute for Quantitive Social Science provided financial support. All errors are our own. 
that are difficult to study with traditional economic data. In fact, economics has best described how macroeconomic constraints such as financial markets or regulation affect entrepreneurial activity; see, for example, Evans and Jovanovic (1989) or Djankov et al. (2000). But few papers have tried to understand what determines why some people go into entrepreneurship and what predicts the success or specific approach to entrepreneurship. There are only a few notable exceptions in economics, such as Landier and Thesmar (2009), who look at demographic and psychological predictors such as who enters into entrepreneurial activity. These factors include risk aversion, IQ, or socioeconomic factors and the occupation of the parents. But the results have been mixed at best and most observables have no predictive power for entry or success in entrepreneurial activities.

In contrast, a large literature in economic sociology and cultural anthropology has highlighted the role of entrepreneurial culture. The influence of culture on entrepreneurship was first emphasized by Weber (1904). Weber argued that the Protestant ethic encouraged a culture that emphasized entrepreneurial vocations. A number of studies document that in many countries around the world, specific subgroups of the population carry a reputation for being particularly adept at running businesses; for example, Marwaris in India, Svabians in Germany, and Esfahanis in Iran. While there are indeed large differences in the fraction of individuals within different groups that are engaged in entrepreneurship, these results are difficult to interpret. The problem is that different ethnic groups might disproportionally adopt entrepreneurship not because of a comparative advantage in that occupation but because of differential access to other opportunities (or lack thereof) for the group. One often discussed example is the situation of Jews in the middle ages in Europe. Since the crafts professions were banned for Jews they were forced to make their livelihood in a different way.

A number of different microchannels have been suggested to operationalize the idea of how an entrepreneurial culture can persist within a community. ${ }^{1}$ One hypothesis is that members of these communities have better business practices and are predisposed to succeed in business since they are learning from very early in their life from family or other members of the community (see Bertrand and Schoar [2006] for a summary of these ideas). An alternative hypothesis assumes that entrepreneurial cultures instill norms of conduct within their community members (through education and upbringing) that promote trust and in turn facilitate trade relationships within the community. Culture here is an implicit enforcement mechanism that allows the members of the community to coordinate on a high trust equilibrium. Adherence to these cultural norms is seen as part of the indi-

1. For the purpose of the chapter we will not try to explain how a specific culture might have come about in the first place; that is, whether it is exogenously given or evolved endogenously in response to environmental constraints. For a detailed description of this debate please resort to two recent articles by Guiso, Sapienza, and Zingales (2006) or Bertrand and Schoar (2006). 
vidual's utility function even in situations where it might be individually optimal to deviate (see, for example, Fukuyama [1996] or Guiso et al. [2006] on the role of trust and culture). Finally, a slightly more functional view of culture has been proposed by Greif (1989), who studied Maghribi traders in the eleventh century. These traders were able to enforce contracts even across large distances due to the tight communication channels between community members. So if one member of the community defrauded another one the whole community would eventually know about it and the perpetrator would not be able to work with anyone in the community again.

In the current study we first document whether there is indeed heterogeneity in the way that entrepreneurs from different communities conduct their business. In particular we ask whether members from so-called entrepreneurial communities differ from other communities in how they set contracts and bargain with customers. Second, we hope to shed some light on the importance of community ties on the business dealings of entrepreneurs. It is important to note that we identify culture here as belonging to a particular ethnic community. Cultural or community affiliation in this chapter should be interpreted in the spirit of Bentheim or Fukuyama as belonging to a cultural identity rather than having distinct social ties within the community as modeled by Greif (1993), since these communities are very large and do not allow for tight social monitoring by group members. We follow Becker $(1998,16)$ in the definition of culture: "Individuals have less control over their culture than over other social capital. They cannot alter their ethnicity, race or family history, and only with difficulty can they change their country or religion. Because of the difficulty of changing culture and its low depreciation rate, culture is largely a 'given' to individuals throughout their lifetimes." Thus, culture may be defined as a set of shared values, beliefs, and norms of a group or community.

For this purpose we conduct a field study in the wholesale market for pens and stationery goods in the South Indian city of Chennai. We select entrepreneurs from three different communities: Andhraites, Marwaris, and Tamilians. Tamilians are the predominant ethnic group in Tamil Nadu. They are usually considered hardworking, conservative in their cultural practices, and honest. The second group is people from Andhra Pradesh, which is a neighboring state to Tamil Nadu. While they are ethnically similar to Tamilians there is some tension between these groups that goes back to the Indian independence. And finally, Marwaris are considered the trader and entrepreneurial community of India who originate from Rajasthan, a state in the North of India. They are a large minority community in Chennai and migrated a long time ago. However, their difference in ethnic background and language makes them easily identifiable as Marwaris. They are usually seen as very shrewd and calculating businesspeople who know how to run a business. However, part of their stereotype is also that they are good to do business with, since they take business transactions very seriously and 
are not driven by emotional considerations. Both of these minority groups present a very sizable fraction of the city population and more generally of India.

To test whether entrepreneurs from different communities vary in their approach to business and in their negotiation outcomes, we randomly assign shoppers from different ethnic groups to visit wholesalers and negotiate a bulk order for pens. We picked the wholesale market for pens since there is wide variety in the ethnic backgrounds of wholesalers in this industry. Moreover, pens are an item that is relatively standardized in its quality but can easily be changed in order size and specificity of the order (since we can customize the pen by printing something on it).

First we find large differences in how entrepreneurs from different communities conduct business. In the negotiation between shoppers and wholesalers, Marwari wholesalers offer significantly lower prices than Tamilian or Andhra wholesalers. Not only is the final price per pen lower but the starting offer of the negotiation is lower in Marwari establishments as well. So the observed lower prices for Marwari wholesalers are not an outcome of poor bargaining on the side of the wholesaler, but seem part of a deliberate strategy. In contrast, wholesalers from Andhra Pradesh offer significantly higher prices at the start of the negotiation and also as a final outcome. Offering a higher price up-front increases short-term profits but can jeopardize the long-run business interest if the wholesaler gets a reputation for high prices. Therefore, offering a lower price can be interpreted as foregoing current profits in order to build a business relationship (or reputation with the client) for the future. ${ }^{2}$

Secondly, we compare business interactions where wholesalers and shoppers are matched across and within cultural or ethnic groups. We find that, on average, wholesalers offer lower prices when there is a match. But we do not find a significant difference in the up-front payments if there is a match. These results suggest that wholesalers favor member from their own community but they do not seem to "trust" them more in the form of requiring lower up-front payment. The reason for this difference in treatment could stem from either a form of taste-based discrimination where wholesalers give better deals to people of their own community since they enjoy the interaction more or have greater ease at communicating. An alternative interpretation suggests that the discount can be seen as an outcome of an implicit norm to treat people from your own community more "fairly." A slightly different version of this interpretation is that wholesalers might feel that people from their own community are more likely than other ethnic groups to return to the wholesaler for more business if they are treated well. Thus, the discount

2. In fact, in our exit interviews Marwari wholesalers stressed the fact that they are trying to build long-term relationships with their customers to increase market share in the intermediate run. 
can be seen as an up-front investment in a long-term relationship. But here as well the underlying assumption is that within-group norms facilitate interactions even when social sanctions are not available.

Finally, we present some results that support the idea that a simple preference-based discrimination story does not seem consistent with our findings on the match variable. To test whether buyers and wholesalers enjoy the business interaction more if there is a match between communities we measure a number of "soft factors" such as pleasantness of facial expressions, whether refreshments are offered, whether the participants are willing to talk about their hometown (which in India is often seen as a way to signal closeness to another person). However, we do not find that these dimensions vary if there is a match in community between buyer and wholesaler. In light of these findings it seems less plausible that the observed in-group favoritism is simply driven by the fact that entrepreneurs enjoy interactions with their own community more. But rather it seems to point toward a tacit understanding about how to treat members from the same community.

The rest of the chapter is structured as follows: section 7.2 provides a review of the related literature, and sections 7.3 and 7.4 lay out the experimental set-up of the audit study and the randomization. In section 7.5 we describe the data. The results from the study are presented in section 7.6 and section 7.7 concludes.

\subsection{Literature Review}

Our study is related to a number of different strands of the literature in economics and psychology. First we draw from the experimental evidence on in-group favoritism, which has a long history in the psychology literature. Beginning with the "Robber's cave experiment" by Sherif et al. (1961), many experiments in psychology have demonstrated in-group favoritism. For instance, Tajfel and Tuner (1979) find evidence of preferential treatment of in-group members over out-group members in reward allocation (even if the groups were arbitrarily defined according to a trivial trait). ${ }^{3}$ The psychology literature draws on the principle of reciprocal altruism proposed by evolutionary scientists to understand in-group favoritism (Axelrod and Hamilton 1981; Trivers 1971).

Yet the presence of in-group favoritism in trust games is fairly mixed. Fershtman and Gneezy (2001), in a trust game played between Ashkenazic and Eastern Jews, do not find evidence of in-group bias. Glaeser et al. (2000) find that the amount sent back by the recipient to the sender in the trust game is higher if both share the same race or nationality. However, they do not find any difference in the amount of money sent by the sender based on the race/nationality of the recipient. They interpret the results as a higher level 
of trustworthiness among in-group members (but no difference in the level of trust among in-groups).

On the other hand, Bernhard, Fehr, and Fischbacher (2006), Gotte, Huffman, and Meier (2006), and Falk and Zender (2007) report significant in-group bias in trust decisions. Bernhard, Fehr, and Fischbacher (2006) study tribes in Papua, New Guinea using a dictator game and find no evidence of hostility between groups in the form of vindictive punishment. However, they find that dictators transfer more to recipients from their own tribe (in-group favoritism). Gotte, Huffman, and Meier (2006) use random assignment of individuals to different platoons during a four-week portion of officer training in the Swiss Army and find a significant increase in willingness to cooperate among fellow platoon members. Falk and Zender (2007) also find evidence of in-group favoritism in a sequential trust game. They find that in-group favoritism is not purely driven by taste but also by expectation of future gains.

Second, our approach is related to the literature of using audit studies to test differences in behaviors across and within groups. We draw heavily from some of the methodological suggestions provided by the following studies even though the context of the prior studies and the questions they address differ completely from the current study. Ayres and Siegelman (1995) examine the negotiation of new car purchases using an audit study and find that dealers quote higher prices to black and female testers as compared to white male testers. For the purpose of his study, auditors from different ethnic groups are randomly assigned to shop at different dealerships. Similarly Newmark, Roy, and Kyle (1996) find evidence of gender discrimination in restaurant hiring using an audit study. Bertrand and Mullainathan (2004) use a field experiment to study discrimination against African-Americans in the labor market. They find that résumés with white names received 50 percent more calls for interviews than résumés with black names.

Finally, our approach contributes to the existing literature on the importance of trust in business transactions. For example, recent papers by Guiso, Sapienza, and Zingales (2006, 2006), and Knack and Keefer (1997) have highlighted the role of cultural factors like trust or social capital for business transactions. An alternative view in economics models cultural ties as a network of interlinking transactions. For example, in Banerjee and Newman (1998) communities serve to coinsure individuals or, in the case of McMillan and Woodruff (1999) or Johnson, McMillan, and Woodruff (2002), as a way to enforce relational contracts.

\subsection{Description of Experimental Setup}

The field experiment was conducted in Chennai, a city in Tamil Nadu, a state in the South of India. Chennai is the largest city in Tamil Nadu, with over 4.5 million inhabitants. For the purpose of the study, we hired auditors 
that belong to the following three communities: Tamil, Andhra, and Rajasthan. The choice of these communities was primarily driven by the fact that the bulk of the entrepreneurs in Chennai are from these communities.

The dominant community in the city is Tamil. Tamilians are ethnically distinct from other Indian communities and also have a strong sense of local patriotism. This assessment is supported by the history of Tamil Nadu. For a detailed description of the history of India after the independence see Guha (2006). For example, Tamil Nadu was one of few states in India that tried to maintain an independent government from Delhi after Indian independence and one of the first states that strongly rejected the selection of Hindi as the national language. There were violent protests in the 1950s when the central government tried to enforce Hindi as the language in schools and local offices. To this date, the fraction of Hindi speakers is very low in Tamil $\mathrm{Nadu}$; much lower than in most other Indian states. The two minority communities that we include in the study are: (a) Andhraites, who are originally from the state of Andhra Pradesh, which is a border state to Tamil Nadu, and (b) Mawaris, who are originally from Rajasthan, a state in the north of India. Both groups have extensive and well-established communities that are present in Chennai.

Andhraites are a small but close-knit community. It is important to note that in the past there were a lot of tensions between Tamil Nadu and Andhra Pradesh. For example, after Indian independence the central government planned to form one state of South India that included Tamil Nadu and Andhra Pradesh. However, violent protests and hunger strikes on both sides forced the establishment of separate states. So while Andhraites are ethnically close to Tamilians, the two communities are quite separate.

Second, Marwaris are considered the trader community of India. They are seen by most Indians as good entrepreneurs and very business savvy individuals. Their language and names make them easily recognizable as Marwaris and their ethnic differences make their physical features distinguishable from the local Tamilians. Marwaris as well as Andhraites live in close-knit ethnic communities and have strong associations to their native place.

To test differences in the bargaining outcomes for these three ethnic groups we chose a single industry, the pen traders, to conduct our transactions. These are wholesale traders in pens and stationery items, not small stationery shops. The choice of this industry was driven by a number of different factors: (a) We were looking for an industry with a large number of similar sized establishments in a given location. Pen and stationery traders/wholesalers provided such an opportunity, since there are more than 100 wholesalers in the Chennai area. Moreover, there is a distinct cluster of wholesalers in a particular neighborhood, called Paris market. The benefit of such an arrangement is that it minimizes the amount of firmspecific shocks. (b) We also needed to find an industry that has a wide variety 
of traders from different ethnic groups, which the pen industry provides. (c) Moreover, we wanted to ensure that the type of commodity we conduct our experiment with is relatively standardized, which in turn facilitates comparisons of deal terms offered by different wholesalers. But at the same time we wanted to make sure that the type of good provides opportunities to include customized features, which will allow us to vary the potential threat of holdup between the buyer and the trader. The pen industry offers a great opportunity since we will be able to customize pens by printing customerspecific logos on them. (d) Finally, the pen industry provides us with a costeffective product of entering into bulk deals.

To implement the actual audit study, we hired auditors who themselves are entrepreneurs so that they are familiar with the process of bargaining for supplies and services. But we verified that the entrepreneurs we hired are not affiliated with the pen industry to avoid any familiarity between the traders and the buyers. Instead, we looked for traders from similar types of businesses such as grocery store owners, small manufacturers, and so forth. Once the auditors were hired, they were provided a half day of training to explain the setup of the experiment, the details of the pen industry, and their particular assignment. The auditors were told that they are part of a study to understand contract terms in the pen industry. They were also told that the study involves auditors from three communities-Tamil, Andhra, and Marwaris - as the majority of the buyers in the pen industry belong to these communities. However, auditors (henceforth referred to as buyers) were not told what the expected outcome of the study is in order to avoid any "demand effects" in their behavior. We also provided buyers with a specific identity, such as the type of firm they run. Most of these business profiles that the buyers were assigned were firms like advertising companies, event management firms, and so forth, which justify why the buyer is placing a bulk order for pens. Buyers are given the name of the firm they operate, the name and logo of the client for whom they are placing the bulk order, and a business card with the associated information to credibly signal to the trader that they run a legitimate business.

We divide the pen purchase by the buyers into two types. In half of the cases the buyers are either assigned to buy plain or printed pens. A printed pen has a firm name or message embossed on it (henceforth referred to as printed pens). In the case of plain pens no embossing is done (plain pens). For example, we refer to a pen as a printed pen if the buyer places an order of pens and gets a company logo printed on it. The distinction between the plain and the printed pen is that the printing on the pen cannot be easily removed and thus destroys its marketability (also it takes on average three days for the wholesaler to get the printing done).

The buyers are asked to place a bulk order of a prespecified order size that we randomized across buyers. The order size varies between 500 to 750 pens in increments of fifty pens. This range of order size was determined after 
conducting a number of pilot interviews with traders who confirmed that this is the modal order size in the wholesale industry. Our aim is to mimic a regular business transaction that is neither too large to draw suspicion nor too small to be negligible by the traders. We varied the size of the order across buyers to test whether effects of ethnicity change when the interaction becomes economically more important.

We also provided the buyers with a detailed script that specified a bargaining rule that they were asked to follow during purchases. The visit to each wholesaler can be summarized as follows. At first the entrepreneur would enter the establishment and buy some items from the wholesaler. Generally these were twenty to twenty-five pens of commonly available brands. The buyer would pay these pens with cash to establish trust between the trader and himself. At the time of making the payment, the buyer would introduce himself to the owner along with the community that he belongs to. ${ }^{4}$ The buyer would also inquire about the community and the place of origin of the owner. ${ }^{5}$ After the introduction, the buyer would reveal to the wholesaler that he is interested in placing a bulk order of between 500 to 750 pens and enquire about the rate. Once the wholesaler makes the first offer, the buyer would make a counteroffer that is equal to the wholesale price of the pen +0.10 Rs. The second and third offer from the buyer would be at $0.10 \mathrm{Rs}$ higher than the previous offer. The fourth offer would be 0.10 Rs lower than the previous offer of the wholesaler. The bargaining ends at any point if the wholesaler agrees on the price or refuses to bargain anymore.

Once the wholesaler and buyer have agreed on the price for printed pens, the buyer would inquire about the printing rate. After fixing the printing rate, the buyer would inquire about the delivery time. If the delivery time were less than a week, the buyer would agree, or else would negotiate for delivery in a week. After finalizing the delivery time, the buyer would negotiate the mode of payment at delivery. The buyer would first ask for credit at the time of delivery, then propose a postdated check, then check payment, and finally cash payment at delivery. After the payment terms are fixed the buyer would ask if he could return the pens in case they are defective. Finally, the buyer would tell the owner that he will come in a week to collect delivery, and at that time the wholesaler would invariably ask for an advance. The buyer would then negotiate for the advance payment using the following rule: 10 percent of the total amount, then 25 percent, and finally 10 percent lower than the wholesaler's final offer. It is important to note that we ask buyers to complete the deal at the lowest price possible, but we did not ask them to terminate the negotiation in case a certain price is not achieved. This means

4. Generally, one could figure out the community from the name and appearance of the buyer.

5. Introducing yourself by mentioning the community one belongs to and asking the other person about their place of origin is common practice in India. 
our experiment does not allow movement along the extensive margin, where some deals might not be reached if the trader insists on a high price.

The bargaining process for nonprinted pens is very similar to the printed pens on all dimensions except for the delivery time. ${ }^{6}$ For the delivery time, the buyer tells the wholesaler that he would like to take delivery after a week even if the wholesaler has the stock ready earlier. ${ }^{7}$ To detect if the buyers deviate from the script and also to check their performance, one of the buyer visits was to a wholesaler who was our representative (the buyers were never informed about this). Furthermore, in some of the other visits, we also had our representatives (whom the buyer was not aware of) visit the wholesaler at the same time as the buyer and witness the bargaining process. ${ }^{8}$

Directly after the visit the buyer is asked to fill out a detailed exit survey that asks about the outcome of the negotiation and other soft factors of the bargaining, such as the friendliness of the trader, whether they offered the buyer refreshment, and whether they talked about their ethnic background; for example, the native village they come from. The buyer would also come back to the wholesaler to pick up the order at the agreed-upon time and pay the outstanding part of the bill.

\subsection{Methodology of Randomization}

The randomization involved matching forty-six buyers to 107 wholesalers and determined the characteristics of each visit for a total of 494 individual visits. Each buyer was assigned to visit eleven different wholesalers. Each wholesaler was visited between three and six times, with the majority of wholesalers being visited five to six times. We stratified the randomization in such a way to ensure that most wholesalers were visited by at least one buyer of each ethnic group. The randomization also imposed that each wholesaler had some visits where the buyer ordered plain pens and in the remaining visits the buyer ordered printed pens. To test how the ethnicity of the buyer interacts with other dimensions of a business transaction, we randomly assigned variation in the type of the order that the buyer placed, such as the type of pen ordered, the number of pens ordered, the number of days until the pens would be picked up, the type of company, and the message printed. We also tried to keep the script for each buyer as consistent as possible across the eleven visits they made to various stores.

To achieve these goals of variation in visit characteristics, while maintaining a similar script across visits for the buyers, the randomization was cal-

6. Also, in case the wholesaler does not ask for any advance, the buyer would propose a token amount of Rs 100 .

7. One of the reasons the buyer would use is that he has to visit other places later and therefore it is difficult to take delivery at that moment.

8. Our representatives would visit the store and inquire about certain items or make a small purchase. 
culated in four main steps. First, each wholesaler and buyer were randomly assigned a profile with their "intrinsic characteristics." Each buyer's ethnic group was, of course, the buyer's actual ethnic group. ${ }^{9}$ The other buyer characteristics were assigned randomly to create variation in the type of transactions. The main dimensions of variation are (a) the buyer's "company type" was assigned from among four categories (event manager, advertising agency, conference organizer, and marketing company). The idea was to pick four different types of firms that are very common in India and justify frequent orders of bulk orders on behalf of other companies. It was important to vary these profiles to avoid suspicion in the minds of the wholesalers in case of frequent interactions with people who have very similar profiles. Buyers were given business cards with the name and their "fictional" company they owned. (b) The "pen type" was assigned from two different pen brands that are of very similar quality and price. Again, this dimension was included to create variation in the type of orders that our buyers place. (c) The "number of pens ordered," in one bulk order varied between 500 and 750 pens in increments of fifty. This variation was included to test how differences in the size of the order affect the bargaining behavior of the wholesalers. (d) The "number of days to have pens held" is the time that the buyers request the bulk order to be ready. This dimension is only binding in the case of printed pens, since nonprinted pens are usually available within a day. This dimension was varied to create heterogeneity between buyers. (e) And finally, we assigned about half of the buyers to buy printed pens and the other half were asked to buy plain pens. For visits with printed pens the buyers were given different logos that the wholesaler would print on the pens. ${ }^{10}$

The randomization also restricted the assignment of buyers based on the location of the wholesaler, which we will refer to as a "location group." Wholesale establishments located near one another (so that wholesalers can see who is visiting a neighboring wholesaler) were assigned the same location group number; on average a location group would contain four to five wholesalers. Buyers would not be assigned to other wholesalers in the same location group. The idea behind this constraint is that it might create awkward interactions for the buyers if a wholesaler who was previously visited sees the same buyer go to a neighboring wholesaler.

In a second step, buyers and wholesalers were randomly assigned to one another in a constrained manner. One wholesaler and one buyer were selected randomly from among the group of wholesalers and the group of buyers. The randomization program then checked that the buyer had not previously been assigned to visit a different wholesaler in that same location group (to avoid the same buyer visiting neighboring wholesaler), and that

9. Thus, the final breakdown of ethnic groups was twenty Tamilian buyers, fifteen Andhra buyers, and fifteen Rajasthani buyers (Marwaris).

10. These characteristics were all stratified within ethnic group. For example, among the ten buyers in each original ethnic, five start with printed visits and five start with plain visits. 
the wholesaler did not have a previously assigned visit by a buyer of that same ethnicity or company type. ${ }^{11}$ If these conditions were met, then this buyer and wholesaler pair was declared a match and the buyer was assigned to visit that wholesaler. The information about the buyer and wholesaler's assigned visits was updated to reflect the new match and both buyer and wholesaler were returned to their respective common pools to be available for future random matches. Once a wholesaler received five visits it was removed from the pool of available wholesalers, while buyers with eleven visits were removed from the pool of buyers. The result of this randomization was that the fifty buyers were each assigned to visit eleven wholesalers, and each wholesaler had a range of buyer types assigned to visit it.

The third step in the randomization was to assign whether the visit was for a plain or a printed pen. Out of the five visits to a wholesaler, two were randomly selected to be plain pen visits, two were randomly selected to be printed pen visits, and the remaining visit was randomly selected to be either a plain or a printed visit. By assigning each visit to be either a printed or plain visit, based on a random stratification at the level of the wholesalers, each buyer ended up with a number of plain visits and a number of printed visits, typically four to seven visits of each type. Finally, each printed pen visit was randomly assigned a logo to be printed on the pen.

A fourth step involved adjusting a few parameters randomly to avoid potential detection by wholesalers. Since the buyers were randomly assigned one pen type, one number of pens to be ordered, and one number of days for pick-up, by chance a few wholesalers had multiple buyers with similar profiles. It was determined that having three or four buyers request the same type of pen or the same number of days before the pick-up of the pens would not arouse suspicion. However, having three or four buyers request the same number of pens could arouse suspicion. Accordingly, for the wholesalers at which three or four buyers were set to ask for the same number of pens, we randomly selected one or two buyers to request 650 pens for their visits to this wholesaler only.

Throughout this randomization, all characteristics were assigned randomly, in either an unconstrained, constrained, or stratified manner. The only aspect of the randomization that was not strictly randomly assigned was the relative timing of the visits, although there was still a great deal of randomly induced variation in this variable. For the most part, visits to different wholesalers by the same buyer were made in a random order, based on the randomly assigned characteristics of the visits. ${ }^{12}$ However, visits to

11. One exception is that if it was the fifth visit to a wholesaler, it was fine for the proposed buyer to have the same company type as an earlier buyer. This was necessary as we only had four company types.

12. For example, whether a visit was a printed- or plain-pen visit was randomly assigned. Each buyer was randomly assigned to start with either the printed-pens script or the plain-pens script. So which of a buyer's visits happened in the first group of visits and which happened in the second group of visits was a randomly assigned value. 
similar areas, especially those outside the main market, were often lumped together to save on transportation costs.

One additional step to the randomization was that some of the initial wholesalers that we had selected for the study stopped selling pens or shut down (even before a single visit was made to the wholesaler). Any visit that was originally scheduled to a wholesaler no longer selling pens or no longer in business was replaced by a visit to an existing or a new wholesaler. ${ }^{13}$ Ideally each "bad" wholesaler would be replaced by one new wholesaler and all remaining visits that were scheduled for the "bad" wholesaler would go to the new replacement wholesaler. In practice, there were not enough new wholesalers to take the place of the "bad" wholesalers. With X new wholesalers available, we randomly selected X of the "bad" wholesalers to be replaced by a randomly selected new wholesaler. For the remaining "bad" wholesalers, for each visit, an existing wholesaler was randomly selected to have the visit go to that wholesaler, meaning this replacement wholesaler then would have six visits in total. ${ }^{14}$

\subsection{Data Description}

The summary statistics in panel A of table 7.1 shows that 107 wholesalers are visited by forty-six buyers. The visits per wholesaler range from two to six with the modal wholesaler receiving five separate visits by different buyers. The modal buyer visits eleven wholesalers. Panel B shows that a majority of visits are to Tamil wholesalers; 297 visits in total. Thirty-nine visits are to Andhra wholesalers, 123 to Marwari wholesalers, and thirty-five visits to wholesalers from other communities. This proportion reflects the proportion of wholesalers in the market. Similarly, column (2) of panel B shows that Tamilian buyers made 180 visits, Andhra buyers made 153, and Marwaris made 161.

Moreover, in table 7.2 we see that the fraction of printed to nonprinted pens is roughly balanced, with 240 visits for printed pens and 254 visits for nonprinted pens. Also the assigned bulk order sizes are evenly distributed between 500 and 750, with the most common lots being 550, 600, and 700. To verify that our regression holds in the smaller sample we regress the different visit characteristics, such as printed versus nonprinted, order size, and time to delivery on the dummies for the ethnic affiliation of the buyers and the wholesalers. We find no significant relationship of the dummy variables to these observable characteristics, which reconfirms that our randomization has been successful.

Table 7.2 also reports the average statistics for the different dimensions of the bargaining outcomes. We show in row (1) that the average price of the

13. We refer to wholesalers who were not in the initial list as new wholesalers (these are not newly opened establishments).

14. For the replacement wholesalers, not as much care was taken with the stratification (e.g., number of buyers of each ethnic group visiting each wholesaler). 
Table 7.1

Summary statistics of the visits

\begin{tabular}{lcccccc}
\hline \multicolumn{7}{c}{ A Visits to each trader by each buyer } \\
\hline & Observations & Mean & Median & $\begin{array}{c}\text { Standard } \\
\text { deviation }\end{array}$ & Min & Max \\
\hline $\begin{array}{l}\text { Total number of traders } \\
\text { Total number of buyers }\end{array}$ & 107 & 4.61 & 5 & 1.05 & 2 & 6 \\
\hline & 46 & 10.73 & 11 & 0.90 & 6 & 13 \\
\hline \multicolumn{7}{c}{ B Decomposition based on ethnic groups } \\
\hline Tamil & Andhra & Marwari & Other & Total visits \\
\hline Number of visits to traders & 297 & 39 & 123 & 35 & 494 \\
Number of visits by buyers & 180 & 153 & 161 & 0 & 494 \\
\hline
\end{tabular}

Table 7.2

Summary statistics of the price and the up-front payment demanded during the visits

\begin{tabular}{lcccccc}
\hline & & & & Standard & & \\
& Observations & Mean & Median & deviation & Min & Max \\
\hline Price & & & & & & \\
$\quad$ Initial offer_printed pen & 240 & 5.33 & 5.22 & 0.772 & 4.0 & 7.5 \\
$\quad$ Final rate_printed pen & 240 & 4.93 & 4.82 & 0.582 & 4.0 & 6.75 \\
$\quad$ Initial offer-nonprinted pen & 254 & 4.90 & 4.8 & 0.665 & 3.8 & 6.5 \\
$\quad$ Final rate-nonprinted pen & 254 & 4.53 & 4.45 & 0.465 & 3.8 & 6 \\
Up-front Payment & & & & & & \\
$\quad$ Initial up-front \%-printed pen & 240 & 0.588 & 0.5 & 0.299 & 0 & 1 \\
Final up-front \%-printed pen & 240 & 0.360 & 0.32 & 0.223 & 0 & 1 \\
$\quad$ Initial up-front \%-nonprinted pen & 254 & 0.192 & 0 & 0.286 & 0 & 1 \\
Final up-front \%-nonprinted pen & 254 & 0.117 & 0 & 0.202 & 0 & 1 \\
\hline
\end{tabular}

Notes: Initial offer rate is the initial price per pen (Rs) offered by the trader. Printed pen refers to a pen on which a buyer gets a message printed. Final rate is the final contracted rate per pen (including printing costs if any). Initial up-front offer is the advance payment demanded by the trader as a fraction of total costs. Final up-front payment is the final advance paid as a fraction of total cost.

printed pen that is offered by the wholesaler at the beginning of the negotiation is Rs 5.33, with a distribution between 4.0 and 7.5. The average initial price offered for a nonprinted pen is Rs 4.9 , with a distribution between 3.8 and 6.5 (row [3]). In contrast, printed pens are on average Rs 0.4 more expensive, with an average final price of 4.93 relative to an average of 4.53 for the nonprinted pens (rows [2] and [4]).

When we turn to the upfront payment that is requested by wholesalers, we can again differentiate between printed-pen purchases and plain-pen purchases. We break out the fraction of the price that is demanded as upfront payment between these two assignments and see in rows (6) and (8) that wholesalers demand a substantially higher up-front payment for printed pens than for plain ones; a mean of 0.36 versus 0.11 , respectively. This difference make sense since the wholesaler faces more risk of losing revenues if the 
buyer does not return to pick up the order in a situation where the pen has been printed upon. It is interesting to see that very few wholesalers demand a 100 percent up-front payment.

\subsection{Results of the Bargaining Process}

\subsubsection{Price Differences Based on the Ethnicity of Buyers and Wholesalers}

We first want to understand whether contractual outcomes and bargaining strategies vary systematically across different ethnic groups, on the side of the buyers as well as the wholesalers. We therefore investigate the most important dimensions of the contract and compare them across visits. These are the price per pen and the amount of upfront payment. In each case we capture the initial offer that is made by the wholesaler and the final amount that is agreed upon after bargaining. We also report a number of "soft factors" that describe whether the treatment of the buyers varies across wholesalers; for example, are buyers offered refreshments or are they treated in a friendly manner? The dimensions of the contract are arrived at through bargaining between the buyer and the wholesaler. As described in the setup, usually the price is the first item that is discussed and then the remaining dimensions are agreed upon. The actual contract is a verbal agreement between the two parties.

In all the tests we conduct following, we will report separate effects for the wholesalers and buyers by ethnic group. However, we want to caveat the results upfront: we believe that the results are more meaningful for the wholesalers rather than for the buyers. While we have more than 100 wholesalers that sell pens, we only have about fifteen to twenty buyers for each ethnic group. This could imply that person-specific effects might be difficult to separate out from the ethnic group average. Moreover, the buyers were chosen and trained by us, which could affect the bargaining strategy they used. Therefore, we put more emphasis on the level effects for the wholesalers. This concern will be much less prevalent in our analysis in the next section where we investigate match-specific outcomes.

We first investigate how the contract terms vary for shoppers and wholesalers from different ethnic groups. In table 7.3 we report the results from a regression of final contracted price per pen on dummies for the ethnicity of the shopper and the wholesaler. As described before, we differentiate between wholesalers who are native Tamilians, and wholesalers from Andhra Pradesh (Andhraites) and those from Rajasthan (Marwaris). In column (1) of table 7.3 we start by including only dummies for the ethnicity of the wholesaler in the regression. We find large and significant differences in the average price of pens depending on the ethnicity of the wholesaler. Establishments run by wholesalers from Andhra on average demand higher prices than 
Table 7.3

Regressions of final rate contracted

\begin{tabular}{|c|c|c|c|c|}
\hline & \multicolumn{4}{|c|}{ Final rate } \\
\hline & (1) & (2) & (3) & (4) \\
\hline Print & $\begin{array}{l}0.388^{* * * *} \\
(0.040)\end{array}$ & $\begin{array}{l}0.389 * * * \\
(0.040)\end{array}$ & $\begin{array}{l}0.384 * * * \\
(0.040)\end{array}$ & $\begin{array}{l}0.389 * * * \\
(0.028)\end{array}$ \\
\hline Location & $\begin{array}{l}0.226^{* * *} \\
(0.085)\end{array}$ & $\begin{array}{l}0.227 * * * \\
(0.083)\end{array}$ & $\begin{array}{l}0.251^{* * * *} \\
(0.082)\end{array}$ & $\begin{array}{l}-0.051 * * * \\
(0.220)\end{array}$ \\
\hline Andhra trader & $\begin{array}{l}0.236^{* * * *} \\
(0.081)\end{array}$ & $\begin{array}{l}0.228^{* * *} \\
(0.079)\end{array}$ & $\begin{array}{l}0.255^{* * * *} \\
(0.074)\end{array}$ & \\
\hline Marwari trader & $\begin{array}{l}-0.551^{* * * *} \\
(0.038)\end{array}$ & $\begin{array}{l}-0.553^{* * * *} \\
(0.037)\end{array}$ & $\begin{array}{l}-0.539 * * * \\
(0.038)\end{array}$ & \\
\hline Other trader & $\begin{array}{l}0.172^{* *} \\
(0.079)\end{array}$ & $\begin{array}{l}0.162^{* *} \\
(0.076)\end{array}$ & $\begin{array}{l}0.155^{* *} \\
(0.079)\end{array}$ & \\
\hline Andhra buyer & & $\begin{array}{r}0.094 * \\
(0.049)\end{array}$ & & $\begin{array}{l}0.107^{* * * *} \\
(0.033)\end{array}$ \\
\hline Marwari buyer & & $\begin{array}{c}-0.081^{*} \\
(0.047)\end{array}$ & & $\begin{array}{c}-0.043 \\
(0.031)\end{array}$ \\
\hline Constant & $\begin{array}{l}4.397 \text { *** } \\
(0.094)\end{array}$ & $\begin{array}{l}4.396^{* * * *} \\
(0.098)\end{array}$ & $\begin{array}{l}4.369 * * * \\
(0.090)\end{array}$ & $\begin{array}{l}4.576^{* * * *} \\
(0.246)\end{array}$ \\
\hline Shopper fixed effect & no & no & yes & no \\
\hline Shop fixed effect & no & no & no & yes \\
\hline$N$ & 494 & 494 & 494 & 494 \\
\hline Adjusted $R^{2}$ & 0.362 & 0.377 & 0.410 & 0.733 \\
\hline
\end{tabular}

Notes: This table reports the results of ordinary least squares (OLS) regressions. The dependent variable is final contracted rate per pen (including printing costs if any). "Print" is a dummy variable that takes the value of 1 if printing was done on the pen. "Location" is a dummy variable that takes the value of one for wholesalers that are not located in the main road. "Andhra trader" and "Marwari trader" are dummy variables that take the value of 1 if the wholesale dealers belong to Andhra and Marwari community, respectively. "Other trader" is a dummy variable that takes the value of 1 if the wholesaler belongs to other community (not a Marwari, Andhra, or Tamil). The omitted category is the Tamil wholesale dealers. "Andhra buyer" and "Marwari buyer" are dummy variables that take the value of 1 if the auditor belongs to Andhra and Marwari community, respectively. The omitted category is the Tamil auditors. White heteroskedasticity consistent standard errors are reported in parentheses.

***Significant at the 1 percent level.

**Significant at the 5 percent level.

*Significant at the 10 percent level.

the Tamil wholesalers. The estimated coefficient is 0.23 , which is about a 5 percent difference in price given that the average pen price is around Rs 4.5. In contrast, Marwari wholesalers offer on average a significantly lower final price to the buyers. The estimated coefficient is 0.55 and the standard error is 0.03 . These results show that Marwari wholesalers on average charge clients a lower price than all other wholesalers, while wholesalers from Andhra offer the highest prices. Note that we also have a dummy for wholesalers who belong to other communities (apart from Marwaris, Tamils, and Andhrites). However, given that the number of wholesalers from other communities is 
very limited, we do not want to place too much weight on the coefficient for other traders.

In column (2) we now repeat this regression but also include dummies for the ethnicity of the shoppers. It is important to control for the ethnicity of the shopper in order to test if wholesalers have different perceptions about the business acumen or trustworthiness of different types of shoppers. We find indeed large differences in the prices paid by shoppers from different ethnic groups. The coefficient on the dummy for shoppers from Andhra Pradesh is 0.09 and significant at 10 percent, which means that these shoppers on average pay more for the pen orders than the Marwari or Tamilian shoppers. In contrast, we find that Marwari shoppers pay less than others (the coefficient on Marwari dummy is -0.08 and significant at 10 percent). The reason why shoppers from different ethnic groups pay differential prices could either be a function of differences in bargaining skills across groups or it could be an outcome of differential treatment by the wholesalers. To shed more light on this question we will analyze the upfront offering behavior of wholesalers in the next section. In columns (3) and (4) of table 7.3 we repeat our regressions including shopper and shop fixed effect, respectively. We do not find any significant changes in the results.

To better understand the bargaining process that leads to the price differences previously reported, we now look at the initial price that the wholesaler offers the shopper before any bargaining happens. This price should not be affected by the "skill" of the individual shopper to bargain the price down, but might instead reflect the wholesaler's expectation about the specific ethnic group that the shopper belongs to. In table 7.4 we repeat the prior regressions but use the initial price per pen that was offered as the dependent variable. We find very similar results to the ones reported in table 7.3. Parallel to our previous findings we find that wholesalers from Andhra Pradesh make much higher initial offers and Marwari wholesalers make lower initial offers than the comparison group, which here (as before) are Tamil wholesalers. In fact, we find that the initial price difference offered by Marwari wholesalers over the Tamilians is even bigger than the final price we found in the first regression (the coefficient is -0.72 and the standard error is 0.6 ). In contrast, the dummy for Andhra wholesalers is 0.27 (with a standard error of 0.10), which is the same size as in the prior regression on the final price. These findings indicate that the different ethnic groups seem to have very different bargaining strategies in terms of the final prices they agree upon and prices they offer as the starting point of the negotiation.

As before, we can also look at the dummies for the ethnicity of the shoppers: Marwari shoppers are asked lower prices upfront than the omitted category (Tamilians). There is, however, no difference in the initial price offer for shoppers from Andhra Pradesh. The difference for Marwari shoppers is about Rs 0.2. In view of the results from table 7.3, where we find that there is not much of a difference in the final price contracted by Marwari shop- 
Table 7.4

Regressions of initial rate offered

\begin{tabular}{lcccc}
\hline & \multicolumn{4}{c}{ Initial rate } \\
\cline { 2 - 5 } & $(1)$ & $(2)$ & $(3)$ & $(4)$ \\
\hline Print & $0.402^{* * *}$ & $0.401^{* * *}$ & $0.386^{* * *}$ & $0.415^{* * *}$ \\
Location & $(0.056)$ & $(0.056)$ & $(0.054)$ & $(0.042)$ \\
& $0.256^{* *}$ & $0.253^{* *}$ & $0.288^{* * *}$ & 0.172 \\
Andhra trader & $(0.109)$ & $(0.108)$ & $(0.100)$ & $(0.467)$ \\
& $0.275^{* * *}$ & $0.265^{* * *}$ & $0.287^{* * *}$ & \\
Marwari trader & $(0.101)$ & $(0.097)$ & $(0.087)$ & \\
& $-0.723^{* * *}$ & $-0.723^{* * *}$ & $-0.721^{* * *}$ & \\
Other trader & $(0.061)$ & $(0.061)$ & $(0.059)$ & \\
& $0.268^{* *}$ & $0.255^{* *}$ & $0.230^{* *}$ & \\
Andhra buyer & $(0.115)$ & $(0.113)$ & $(0.108)$ & 0.001 \\
& & -0.004 & & $(0.049)$ \\
Marwari buyer & & $(0.069)$ & & $-0.126^{* * *}$ \\
& & $-0.175^{* *}$ & & $(0.046)$ \\
Constant & $(0.068)$ & & $4.763^{* * *}$ \\
& & $3.768^{* * *}$ & $4.749^{* * *}$ & $(0.517)$ \\
Shopper fixed effect & $(0.125)$ & $(0.150)$ & $(0.116)$ & no \\
Shop fixed effect & no & no & yes & yes \\
$N$ & no & no & no & 494 \\
$R^{2}$ & 494 & 494 & 494 & 0.667 \\
\hline
\end{tabular}

Notes: This table reports the results of ordinary least squares (OLS) regressions. The dependent variable is "Initial rate" offered per pen (including printing costs if any). "Print" is a dummy variable that takes the value of 1 if printing was done on the pen. "Location" is a dummy variable that takes the value of one for wholesalers that are not located in the main road. "Andhra trader" and "Marwari trader" are dummy variables that take the value of 1 if the wholesale dealers belong to Andhra and Marwari community, respectively. "Other trader" is a dummy variable that takes the value of 1 if the wholesaler belongs to other community (not a Marwari, Andhra, or Tamil). The omitted category is the Tamil wholesale dealers. "Andhra buyer" and "Marwari buyer" are dummy variables that take the value of 1 if the auditor belongs to Andhra and Marwari community, respectively. The omitted category is the Tamil auditors. White heteroskedasticity consistent standard errors are reported in parentheses.

***Significant at the 1 percent level.

**Significant at the 5 percent level.

*Significant at the 10 percent level.

pers, this suggests that wholesalers offer shoppers from other ethnic groups higher prices to begin with and then get bargained down. In contrast, they offer Marwari shoppers lower prices upfront.

In table 7.6, we examine the differences in the bargaining dynamics directly by looking at the change in prices between the initial offer and the final contracted price. The results in column (1) confirm that Marwari wholesalers grant smaller reductions in the final price (relative to the initial offer) as compared to Tamil or Andhra wholesalers. On the side of the shoppers, we find that Andhra or Marwari shoppers obtain smaller price reductions after bargaining than Tamil shoppers. However, the reasons for this dynamic might 
give a distorted reflection of the shopper's performance: Marwari shoppers are offered low prices from the beginning and thus might not be able to get much better deals. On the other hand, Andhra shoppers are offered higher prices upfront but end up with higher final offers as well.

Interestingly, these results seem to suggest a different offer behavior between Marwaris and other wholesalers. Marwari wholesalers seem to quote the best price upfront that they are willing to offer (or close to the best price) and then do not bargain much with the clients. In contrast, Andhra wholesalers start at a much higher price and then allow themselves to be bargained down. There are two possible interpretations for this finding: one could either infer that Marwari traders are indeed worse businesspeople than the other groups, since they seem to undercharge and thus do not extract the full surplus from the buyers. Under this interpretation the fact that Andhra wholesalers start and end at a higher price means that they are strategically better in the bargaining process. However, an alternative interpretation would take into account the repeated nature of the interaction. If Marwari traders see each deal as a way to build a reputation with their clients by offering good prices, the observed outcome would represent forward-looking behavior by the Marwari traders. In fact, in the qualitative debriefing with the buyers after the visits, we heard many times that the Marwari traders would mention to the buyers that they were giving them a good price to set up a long-term relationship with the clients and that they hoped the buyer would bring them future business. Furthermore, given that we also find that wholesalers offer Marwari buyers lower prices up-front, it does not appear that wholesalers perceive Marwaris to lack bargaining skills. Thus, the latter interpretation seems to be more plausible based on the findings so far. In the following tests we will shed more light on this. ${ }^{15}$

\subsubsection{Differences in Upfront Payment Based on the Ethnicity of Shoppers and Wholesalers}

In table 7.5 we look at the amount of advance payment that is requested by the wholesalers, which is the second important dimension of the contract. We follow the same sequence of regressions as in table 7.3 and 7.4. The upfront payment is important if the wholesaler is concerned that the buyer might not come back to pick up the pens. This concern might be valid, in particular, in the case of printed pens that are more customized and thus cannot be easily reused by the wholesaler. As described before, we made sure that the logos printed on the pens were very difficult to remove so that the holdup issue from the side of the buyer is a valid concern. In column (1) of table 7.5 we regress the fraction of up-front payment that is agreed upon on dummies for the ethnic background of the shoppers and wholesalers, as

15. As discussed before, it is important to remember that in our experimental setup we asked buyers to conduct the deal and not to walk out in case the trader does not agree to a lower price. Therefore, we do not observe any movement along the extensive margin, which could be much higher for Andhra traders if they insist on charging higher prices. 
Table 7.5

Regressions of upfront payment demanded

\begin{tabular}{|c|c|c|c|c|c|c|}
\hline & \multicolumn{3}{|c|}{ Final up-front payment } & \multicolumn{3}{|c|}{ Initial up-front payment } \\
\hline & (1) & (2) & (3) & (4) & (5) & (6) \\
\hline \multirow[t]{2}{*}{ Print } & $0.273^{* * *}$ & $0.241 * * *$ & $0.230 * * *$ & $0.393^{* * *}$ & $0.381^{* * *}$ & $0.388 * * *$ \\
\hline & $(0.029)$ & $(0.017)$ & $(0.018)$ & $(0.025)$ & $(0.025)$ & $(0.026)$ \\
\hline \multirow[t]{2}{*}{ Location } & $0.086^{* *}$ & 0.003 & -0.081 & 0.012 & 0.0004 & 0.060 \\
\hline & $(0.043)$ & $(0.029)$ & $(0.070)$ & $(0.048)$ & $(0.043)$ & $(0.115)$ \\
\hline \multirow[t]{2}{*}{ Andhra trader } & $0.117^{* * *}$ & $0.107^{* * *}$ & & $0.100^{*}$ & $0.090^{*}$ & \\
\hline & $(0.045)$ & $(0.045)$ & & $(0.052)$ & $(0.050)$ & \\
\hline \multirow[t]{2}{*}{ Marwari trader } & $-0.055^{* * *}$ & $-0.057 * * *$ & & $-0.104 * * *$ & $-0.112^{* * *}$ & \\
\hline & $(0.018)$ & $(0.018)$ & & $(0.027)$ & $(0.027)$ & \\
\hline \multirow[t]{2}{*}{ Other trader } & 0.050 & 0.027 & & 0.080 & 0.052 & \\
\hline & $(0.036)$ & (0.029) & & $(0.051)$ & $(0.046)$ & \\
\hline \multirow[t]{2}{*}{ Andhra buyer } & $0.073 * * *$ & & $0.066 * * *$ & $0.071 * *$ & & $0.063 * *$ \\
\hline & $(0.020)$ & & $(0.019)$ & $(0.029)$ & & $(0.029)$ \\
\hline \multirow[t]{2}{*}{ Marwari buyer } & $0.064^{* * *}$ & & $0.055^{* * *}$ & $0.099 * * *$ & & $0.086^{* * *}$ \\
\hline & $(0.022)$ & & $(0.021)$ & $(0.031)$ & & $(0.030)$ \\
\hline \multirow[t]{2}{*}{ Constant } & $0.076^{*}$ & $0.118 * * *$ & $0.173 * *$ & $0.137 * *$ & $0.216^{* * *}$ & 0.082 \\
\hline & $(0.039)$ & $(0.037)$ & $(0.080)$ & $(0.058)$ & $(0.052)$ & $(0.129)$ \\
\hline Shopper fixed effect & no & yes & no & no & yes & no \\
\hline Shop fixed effect & no & no & yes & no & no & yes \\
\hline$N$ & 494 & 494 & 494 & 494 & 494 & 494 \\
\hline$R^{2}$ & 0.298 & 0.418 & 0.426 & 0.357 & 0.436 & 0.442 \\
\hline
\end{tabular}

Notes: This table reports the results of OLS regressions. The dependent variables are "Final up-front payment" (final advance paid as a fraction of total cost) and "Initial up-front payment." "Print" is a dummy variable that takes the value of 1 if printing was done on the pen. "Location" is a dummy variable that takes the value of one for wholesalers that are not located in the main road. "Andhra trader" and "Marwari trader" are dummy variables that take the value of 1 if the wholesale dealers belong to Andhra and Marwari community, respectively. "Other trader" is a dummy variable that takes the value of 1 if the wholesaler belongs to other community (not a Marwari, Andhra or Tamil). The omitted category is the Tamil wholesale dealers. "Andhra buyer" and "Marwari buyer" are dummy variables that take the value of 1 if the auditor belongs to Andhra and Marwari community, respectively. The omitted category is the Tamil auditors. White heteroskedasticity consistent standard errors are reported in parentheses.

*** Significant at the 1 percent level.

**Significant at the 5 percent level.

*Significant at the 10 percent level.

well as controls for the types of pens and the location of the shop. As one might have expected, we find that printed pens require 27 percent higher up-front payment than nonprinted pens. See Iyer and Schoar (2008) for a more detailed analysis of the role of relationship-specific investments. But when looking at the different ethnic groups, we find that Andhra wholesalers ask for a 10 percent higher up-front payment and Marwari wholesalers ask for 5 percent lower up-front payments on average, compared to Tamil wholesalers. Similarly, the shopper dummies show that both Marwari and Andhra shoppers on average are asked for a higher upfront payment than Tamilians.

Interestingly, these results confirm that on the dimension of up-front pay- 
ments, as well, there are differences in bargaining outcomes across ethnic groups. In contrast to what local stereotypes might have predicted, Marwari wholesalers offer the lowest up-front payments. This might either be a sign that they are the most generous and trusting or, alternatively, it could signal that they are willing to take more risk in their relationship with customers. To try and shed light on the underlying drivers of these results, we will now look at the interaction across and within ethnic groups.

\subsubsection{Importance of a Match between the Ethnicity of Buyer and Wholesaler}

We now investigate whether the terms of the business transaction change when there is a match between ethnic groups; that is, a Marwari buyer meeting a Marwari trader versus a trader from a different ethnic group. We create a variable called "match" that is 1 if the ethnicity of the buyer and wholesaler are the same (Andhra, Marwari, or Tamil), and zero otherwise. We again regress the price per pen and the fraction of up-front payment on the match indicator, controls for the different ethnic groups, and location and printed pen dummies. Column (1) of table 7.6 shows that the final price at which the pens are sold is significantly lower when there is a match based on ethnicity between the buyer and the wholesaler. The coefficient on the "match" dummy is 0.07 with a standard error of 0.03 . This result suggests that buyers receive, on average, a discounted price if they are randomly matched with a wholesaler from their own ethnic group. Note that we do not include dummies for ethnicity of buyer and wholesaler as we include both shop and shopper-fixed effects. We repeat a parallel regression for the initial price that the wholesaler offers at the beginning of the bargaining. In column (2) of table 7.7 we again find that the coefficient on the match variable is negative and significant. These results show that wholesalers immediately offer buyers from their own ethnic group a better deal up-front. Thus the results on the "match" variable is not primarily driven by a more favorable negotiation process when people of the same ethnic group meet, but it seems that even in the initial reaction a wholesaler is more generous when meeting someone of the same community. It is important to remember that the wholesaler knows the community of the shopper from the beginning of the negotiation, since our bargaining script ensures that the shopper has introduced his community before the negotiation starts. This finding also helps to address the concern that the effect of the match variable is demand driven (auditors anticipate the purpose of the study and thus negotiate harder when they meet someone of their own ethnic group). ${ }^{16}$

16. These findings also assuage a different concern about the match in ethnicity between buyers and wholesalers. If buyers and wholesalers from the same community indeed knew each other outside of the actual experiment one could be concerned that they would make a deal with each other to charge a very high price and then split the difference between each other. While we have put a large number of controls in place to monitor any such behavior, it is reassuring to see that this concern is also not borne out in the data. 
Table 7.6

Regressions of bargaining on price and up-front

\begin{tabular}{|c|c|c|c|c|}
\hline & \multicolumn{2}{|c|}{ Price difference } & \multicolumn{2}{|c|}{ Advance difference } \\
\hline & (1) & (2) & (3) & (4) \\
\hline Print & $\begin{array}{c}-0.002 \\
(0.006)\end{array}$ & $\begin{array}{l}-0.003 \\
(0.005)\end{array}$ & $\begin{array}{c}-0.038 \\
(0.033)\end{array}$ & $\begin{array}{l}-0.038 \\
(0.042)\end{array}$ \\
\hline Location & $\begin{array}{c}0.004 \\
(0.009)\end{array}$ & $\begin{array}{c}0.004 \\
(0.008)\end{array}$ & $\begin{array}{c}0.009 \\
(0.051)\end{array}$ & $\begin{array}{c}0.007 \\
(0.051)\end{array}$ \\
\hline Andhra trader & $\begin{array}{c}0.004 \\
(0.009)\end{array}$ & $\begin{array}{c}0.004 \\
(0.009)\end{array}$ & $\begin{array}{c}-0.062 \\
(0.046)\end{array}$ & $\begin{array}{c}-0.064 \\
(0.047)\end{array}$ \\
\hline Marwari trader & $\begin{array}{l}-0.027 * * * \\
(0.006)\end{array}$ & $\begin{array}{l}-0.027 * * * \\
(0.006)\end{array}$ & $\begin{array}{l}-0.004 \\
(0.035)\end{array}$ & $\begin{array}{l}-0.005 \\
(0.034)\end{array}$ \\
\hline Other trader & $\begin{array}{c}0.012 \\
(0.011)\end{array}$ & $\begin{array}{c}0.011 \\
(0.011)\end{array}$ & $\begin{array}{c}0.003 \\
(0.051)\end{array}$ & $\begin{array}{c}0.008 \\
(0.050)\end{array}$ \\
\hline Andhra buyer & & $\begin{array}{l}-0.017 * * * \\
(0.006)\end{array}$ & & $\begin{array}{l}-0.087 * * * \\
(0.033)\end{array}$ \\
\hline Marwari buyer & & $\begin{array}{l}-0.014^{* *} \\
(0.006)\end{array}$ & & $\begin{array}{c}-0.022 \\
(0.034)\end{array}$ \\
\hline Constant & $\begin{array}{l}0.071 * * * \\
(0.010)\end{array}$ & $\begin{array}{l}0.082^{* * * *} \\
(0.011)\end{array}$ & $\begin{array}{l}0.039 * * * \\
(0.066)\end{array}$ & $\begin{array}{l}0.433^{* * * *} \\
(0.070)\end{array}$ \\
\hline$N$ & 494 & 494 & 343 & 343 \\
\hline$R^{2}$ & 0.053 & 0.071 & 0.009 & 0.029 \\
\hline
\end{tabular}

Notes: This table reports the results of OLS regressions. The dependent variables are "Price difference" (Initial rate-final rate/initial rate) and "Advance difference" (Initial up-front-Final up-front/initial upfront). "Print" is a dummy variable that takes the value of 1 if printing was done on the pen. "Location" is a dummy variable that takes the value of one for wholesalers that are not located in the main road. "Andhra trader" and "Marwari trader" are dummy variables that take the value of 1 if the wholesale dealers belong to Andhra and Marwari community, respectively. "Other trader" is a dummy variable that takes the value of 1 if the wholesaler belongs to other community (not a Marwari, Andhra, or Tamil). The omitted category is the Tamil wholesale dealers. "Andhra buyer" and "Marwari buyer" are dummy variables that take the value of 1 if the auditor belongs to Andhra and Marwari community, respectively. The omitted category is the Tamil auditors. White heteroskedasticity consistent standard errors are reported in parentheses.

***Significant at the 1 percent level.

**Significant at the 5 percent level.

*Significant at the 10 percent level.

In the next step we look at the up-front payments charged by the wholesalers and compare them between matched and nonmatched candidates. If community affiliation serves as a trust indicator we would expect to see lower up-front payments on average, when business parties of the same ethnic community are matched. Column (3) replicates our standard regression using the fraction of requested up-front payment as the dependent variable. The results suggest that on average wholesalers do not seem to ask for a different (smaller) up-front payment if the buyer is from the same ethnic group; the coefficient on the match variable is 0.01 and the standard errors are high. In column (4) when we regress the initial fraction of up-front pay- 
Table 7.7

Does match of ethnicity between trader and buyer matter?

\begin{tabular}{lcccc}
\hline & $\begin{array}{c}\text { Final rate } \\
(1)\end{array}$ & $\begin{array}{c}\text { Initial rate } \\
(2)\end{array}$ & $\begin{array}{c}\text { Final up-front } \\
(3)\end{array}$ & $\begin{array}{c}\text { Initial up-front } \\
(4)\end{array}$ \\
\hline Print & $0.395^{* * *}$ & $0.400^{* * *}$ & $0.230^{* * * *}$ & $0.375^{* * *}$ \\
& $(0.027)$ & $(0.037)$ & $(0.017)$ & $(0.026)$ \\
Location & 0.329 & 0.456 & $-0.083^{* *}$ & 0.011 \\
& $(0.224)$ & $(0.400)$ & $(0.040)$ & $(0.208)$ \\
Match & $-0.071^{* *}$ & $-0.130^{* * *}$ & 0.010 & 0.008 \\
& $(0.033)$ & $(0.045)$ & $(0.020)$ & $(0.029)$ \\
Constant & $4.148^{* * *}$ & $4.762^{* * *}$ & 0.251 & $-0.119^{* *}$ \\
& $(0.264)$ & $(0.480)$ & $(0.173)$ & $(0.058)$ \\
Shop fixed effects & yes & yes & yes & yes \\
Shopper fixed effect & yes & yes & yes & yes \\
$N$ & 494 & 494 & 494 & 494 \\
$R^{2}$ & 0.779 & 0.746 & 0.524 & 0.508 \\
\hline
\end{tabular}

Notes: This table reports the results of OLS regressions. The dependent variables are "Final rate" per pen, "Initial rate" offered, "Final up-front" payment (final advance paid as a fraction of total cost). "Print" is a dummy variable that takes the value of 1 if printing was done on the pen. "Location" is a dummy variable that takes the value of one for wholesalers that are not located in the main road. Andhra trader and Marwari trader are dummy variables that take the value of 1 if the wholesale dealers belong to Andhra and Marwari community, respectively. The omitted category is the Tamil wholesale dealers. Andhra buyer and Marwari buyer are dummy variables that take the value of 1 if the auditor belongs to Andhra and Marwari community, respectively. The omitted category is the Tamil auditors. "Match" is a dummy variable that takes the value of 1 if the wholesale dealer and Buyer are from the same ethnic group (Tamil-Tamil, Andhra-Andhra, and Marwari-Marwari). White heteroskedasticity consistent standard errors are reported in parentheses.

*** Significant at the 1 percent level.

**Significant at the 5 percent level.

*Significant at the 10 percent level.

ment on the match dummy and the other control variables, we again see that the coefficient on the match dummy is insignificant and close to zero. This result is surprising, especially in light of the earlier findings. It appears that in this context community matches are not useful in affecting the level of trust in the counterparty but seem to show preference-based "discrimination," since the wholesalers are willing to give the shopper a better deal on the purchase.

\subsubsection{Importance of a Match across Individual Ethnic Communities}

To understand the effects of the ethnicity match between buyers and wholesalers in more detail, in table 7.8 we now create separate dummies for matches across different ethnic groups (e.g., Andhra-Andhra, TamilTamil, and Marwari-Marwari). In column (1) we regress the final price for the pens on the set of dummies for each of the matches (the omitted group being cross-matches). When we compare discounts given by wholesalers of different ethnic backgrounds, we find that the one group that offers higher 
Table 7.8

The importance of ethnicity match between trader and buyer

\begin{tabular}{|c|c|c|c|c|}
\hline & \multicolumn{2}{|c|}{ Final rate } & \multicolumn{2}{|c|}{ Final up-front } \\
\hline & (1) & (2) & (3) & (4) \\
\hline Print & $\begin{array}{l}0.380^{* * *} \\
(0.040)\end{array}$ & $\begin{array}{l}0.388 * * * \\
(0.027)\end{array}$ & $\begin{array}{l}0.242^{* * *} \\
(0.018)\end{array}$ & $\begin{array}{l}0.227^{* * *} \\
(0.017)\end{array}$ \\
\hline Location & $\begin{array}{l}0.219^{* * * *} \\
(0.083)\end{array}$ & $\begin{array}{l}0.259 \\
(0.233)\end{array}$ & $\begin{array}{l}-0.002 \\
(0.031)\end{array}$ & $\begin{array}{l}-0.131 \\
(0.151)\end{array}$ \\
\hline $\begin{array}{l}\text { Andhra buyer and } \\
\text { Andhra trader }\end{array}$ & $\begin{array}{l}-0.064 \\
(0.154)\end{array}$ & $\begin{array}{l}-0.089 \\
(0.124)\end{array}$ & $\begin{array}{l}-0.046 \\
(0.093)\end{array}$ & $\begin{array}{l}-0.044 \\
(0.067)\end{array}$ \\
\hline $\begin{array}{l}\text { Tamil buyer and } \\
\text { Tamil trader }\end{array}$ & $\begin{array}{l}-0.181^{* * * *} \\
(0.085)\end{array}$ & $\begin{array}{l}-0.143^{* * * *} \\
(0.055)\end{array}$ & $\begin{array}{c}0.005 \\
(0.039)\end{array}$ & $\begin{array}{l}-0.010 \\
(0.034)\end{array}$ \\
\hline $\begin{array}{l}\text { Marwari buyer and } \\
\text { Marwari trader }\end{array}$ & $\begin{array}{c}0.105 \\
(0.081)\end{array}$ & $\begin{array}{c}0.029 \\
(0.061)\end{array}$ & $\begin{array}{c}0.030 \\
(0.047)\end{array}$ & $\begin{array}{l}0.060 \\
(0.046)\end{array}$ \\
\hline Andhra trader & $\begin{array}{c}0.179^{*} \\
(0.097)\end{array}$ & & $\begin{array}{l}0.134 * * \\
(0.062)\end{array}$ & \\
\hline Marwari trader & $\begin{array}{l}-0.653^{* * * *} \\
(0.061)\end{array}$ & & $\begin{array}{l}-0.063 * * \\
(0.030)\end{array}$ & \\
\hline Other trader & $\begin{array}{c}0.090 \\
(0.084)\end{array}$ & & $\begin{array}{c}0.051 \\
(0.042)\end{array}$ & \\
\hline Andhra buyer & $\begin{array}{c}-0.007 \\
(0.060)\end{array}$ & & $\begin{array}{l}0.080^{* * * *} \\
(0.030)\end{array}$ & \\
\hline Marwari buyer & $\begin{array}{l}-0.218^{* * * *} \\
(0.076)\end{array}$ & & $\begin{array}{l}0.060 \\
(0.039)\end{array}$ & \\
\hline Constant & $\begin{array}{l}4.550^{* * *} \\
(0.119)\end{array}$ & $\begin{array}{l}4.270 * * * \\
(0.278)\end{array}$ & $\begin{array}{c}0.074 \\
(0.055)\end{array}$ & $\begin{array}{c}0.290 \\
(0.181)\end{array}$ \\
\hline Shopper fixed effect & no & yes & no & yes \\
\hline Shop fixed effect & no & yes & no & yes \\
\hline $\begin{array}{l}N \\
R^{2}\end{array}$ & $\begin{array}{c}494 \\
0.383\end{array}$ & $\begin{array}{c}494 \\
0.779\end{array}$ & $\begin{array}{c}494 \\
0.300\end{array}$ & $\begin{array}{c}494 \\
0.524\end{array}$ \\
\hline
\end{tabular}

Notes: This table reports the results of OLS regressions (without a constant). The dependent variables are "Final rate" and "Final up-front." "Print" is a dummy variable that takes the value of 1 if printing was done on the pen. "Location" is a dummy variable that takes the value of one for wholesalers that are not located in the main road. "Andhra buyer" and "Andhra trader" represents the match when an "Andhra buyer" meets an Andhra Wholesale dealer, similarly for other matches. Note that there was no match in the data between "Marwari buyer" and Andhra dealer. White heteroskedasticity consistent standard errors are reported in parentheses.

*** Significant at the 1 percent level.

**Significant at the 5 percent level.

*Significant at the 10 percent level.

discounts to buyers of their own community are Tamil wholesalers. We do not find significant differences in the discounts granted when there is an Andhra-Andhra match or Marwari-Marwari match. The previous results hold even after controlling for wholesaler and shopper fixed effects (column [2]).

In column (3) of table 7.8 we repeat the same regression setup but we now 
use the percentage of advance payment asked for as a percentage of the total cost of the transaction. As before, we assume that the amount of up-front payment required should vary with the wholesalers' trust in the buyer. We do not find that the coefficients on the Andhra-Andhra match are significantly different from zero. That means Andhra wholesalers do not grant shoppers from their community more favorable terms up-front. We find a similar result for the Marwari-Marwari interactions. In contrast to the findings in column (1) and (2), in situations where we have Tamil-Tamil matches, we do not find a significant discount in the required up-front pay. Thus, while Tamil wholesalers are willing to offer significantly lower prices when they meet a Tamil buyer, they do not lower the required up-front payment.

These results are quite surprising. As discussed before, given the setup of this experiment, it is implausible that effective social sanctions can explain why parties might agree to better contractual terms when they are matched with shoppers from their own community, since the community ties in a city of the size of Chennai are low. Interestingly, we do not find that community matches lead to smaller up-front payments. In addition, we find that significantly lower prices are offered to their own community buyers by Tamilian wholesalers. However, since this is the largest community with more than four million Tamilians in Chennai, it might be more difficult to believe that Tamilians have to fear the social sanctions within their own ethnic group. Thus, unlike the results in Greif (1993), it is highly unlikely that social sanctions within ethnic groups are the main driver of the results.

One possible explanation could be that differences in treatment between ethnic groups are primarily driven by preference-based discrimination. If traders prefer to do business with people from their own community they might feel more inclined to offer them better deal terms (henceforth referred to as "preference hypothesis"). The idea behind preference-based discrimination could be that traders enjoy dealing with people from their own community or feel greater ease of interacting and thus are willing to forgo a bigger fraction of their profits. A variation on the preference-based explanation is that social norms or expectations dictate how to behave to people from your own community; for example, wholesalers might feel compelled to offer fairer deals. An alternative view is that wholesalers expect that people from their own community are more likely to come back and provide future business if they get a good deal the first time around. Here the "trust" is that traders might expect buyers from their own community to reciprocate more strongly to a fair deal by giving more future business to that wholesaler.

\subsubsection{Do Soft Factors Matter in Bargaining?}

To help differentiate between the preference-based and the reciprocitybased hypothesis, we examine how the social factors interact with a match between shopper and wholesaler. If preference-based explanations indeed explain the better treatment of buyers from the same ethnic group, should 
we see a more pleasant interaction between shoppers and wholesalers in the case of a match? For that purpose we also coded a detailed description of soft factors of the interaction between the shoppers and wholesalers during the negotiation. The variables we coded to measure the quality of the interaction are the facial expression of the buyers during the negotiation and whether traders offered the buyers refreshment.

In table 7.9 we first investigate whether indeed buyers from the same community report more positive interactions with traders from their community. In column (1) we regress a dummy for whether the trader initially greeted the buyer with a positive facial expression on our standard dummies for the ethnic background of the buyers and wholesalers. We do not find significant differences either across wholesalers or across buyers. In column (2), we introduce the match variable. We control for the location of the wholesaler, and the type of pen that we requested in addition to the shop and shopperfixed effects. We find that the coefficient on the match variable is positive but not significant. In columns (3) and (4) we repeat the same regressions but use the facial expression at the end of the interview. Again, we find no significant difference in the interaction when there is a match between ethnic groups. Interestingly, we find that Andhra buyers report a more positive facial expression at the end of the transaction. This could be driven partly by the fact that Andhra buyers also pay higher prices. The third dimension we capture is whether the trader offered refreshment to the buyer. Columns (5) and (6) report the results from these regressions. We again do not find significant differences for interactions where a buyer from the same ethnic group interacts with the trader. ${ }^{17}$ We do, however, find that Marwari wholesalers are more likely to offer refreshments to their customers and Andhra buyers are also more likely to be offered refreshments from wholesalers.

What is interesting about these results is that there does not seem to be an immediately observable, more positive interaction between shopper and wholesaler (as reported by the shopper) when the two parties are from the same community. However, at the same time our prior results indicated that in deal situations where there is a match, the shopper receives a better price and no difference in the up-front. This might suggest that the differential treatment based on the community match does not seem to be driven by simply having a more enjoyable interaction. Instead, it might be explained by social norm or expectations that parties from the same community should treat each other "fairly." Again, it is important to note that our results cannot be due to social enforcement since the size of the "community" here is much too large to allow for any peer monitoring.

In unreported regressions we now run a horse race between the match

17. Note that we also repeated the regressions reported previously by breaking down the match variable across different ethnic groups (similar to table 7.8 ). We did not find any significant difference in soft factors across different ethnic groups (not reported). 
What factors matter in the quality of interaction?

\begin{tabular}{|c|c|c|c|c|c|c|}
\hline & \multicolumn{2}{|c|}{ Initial expression } & \multicolumn{2}{|c|}{ Final expression } & \multicolumn{2}{|c|}{ Anything offered } \\
\hline & (1) & (2) & (3) & (4) & $(5)$ & (6) \\
\hline Print & $\begin{array}{l}-0.029 \\
(0.044)\end{array}$ & $\begin{array}{c}0.018 \\
(0.038)\end{array}$ & $\begin{array}{c}0.036 \\
(0.030)\end{array}$ & $\begin{array}{c}0.053^{*} \\
(0.030)\end{array}$ & $\begin{array}{l}0.106^{* *} \\
(0.051)\end{array}$ & $\begin{array}{r}0.083^{*} \\
(0.045)\end{array}$ \\
\hline Location & $\begin{array}{c}0.036 \\
(0.069)\end{array}$ & $\begin{array}{c}0.016 \\
(0.270)\end{array}$ & $\begin{array}{c}0.011 \\
(0.051)\end{array}$ & $\begin{array}{c}-0.075 \\
(0.098)\end{array}$ & $\begin{array}{c}0.219 \\
(0.098)\end{array}$ & $\begin{array}{l}-0.027 \\
(0.515)\end{array}$ \\
\hline Andhra trader & $\begin{array}{l}-0.020 \\
(0.089)\end{array}$ & & $\begin{array}{c}-0.003 \\
(0.067)\end{array}$ & & $\begin{array}{c}0.102 \\
(0.094)\end{array}$ & \\
\hline Marwari trader & $\begin{array}{c}0.013 \\
(0.052)\end{array}$ & & $\begin{array}{c}0.019 \\
(0.032)\end{array}$ & & $\begin{array}{l}0.135^{* *} \\
(0.061)\end{array}$ & \\
\hline Other trader & $\begin{array}{c}0.096 \\
(0.074)\end{array}$ & & $\begin{array}{c}0.041 \\
(0.045)\end{array}$ & & $\begin{array}{c}0.073 \\
(0.098)\end{array}$ & \\
\hline Andhra buyer & $\begin{array}{l}0.218 \\
(0.055)\end{array}$ & & $\begin{array}{l}0.076^{* *} \\
(0.036)\end{array}$ & & $\begin{array}{l}0.136^{* *} \\
(0.059)\end{array}$ & \\
\hline Marwari buyer & $\begin{array}{c}0.162 \\
(0.056)\end{array}$ & & $\begin{array}{c}0.054 \\
(0.039)\end{array}$ & & $\begin{array}{c}0.103 \\
(0.063)\end{array}$ & \\
\hline Match & & $\begin{array}{c}0.030 \\
(0.047)\end{array}$ & & $\begin{array}{c}-0.022 \\
(0.039)\end{array}$ & & $\begin{array}{c}0.081 \\
(0.056)\end{array}$ \\
\hline Constant & $\begin{array}{l}1.649 * * * \\
(0.091)\end{array}$ & $\begin{array}{l}1.804^{* * * *} \\
(0.311)\end{array}$ & $\begin{array}{l}-1.947 \\
(2.460)\end{array}$ & $\begin{array}{l}1.871^{* *} \\
(0.135)\end{array}$ & $\begin{array}{c}0.118 \\
(0.118)\end{array}$ & $\begin{array}{c}0.556 \\
(0.590)\end{array}$ \\
\hline Shop fixed effect & no & yes & no & yes & no & yes \\
\hline Shopper fixed effect & no & yes & no & yes & no & yes \\
\hline$N$ & 494 & 494 & 493 & 493 & 494 & 494 \\
\hline$R^{2}$ & 0.039 & 0.318 & 0.013 & 0.031 & 0.041 & 0.368 \\
\hline
\end{tabular}

Notes: This table reports the results of OLS regressions. The dependent variables are: "Initial expression," "Final expression," and "Anything offered." "Initial expression" takes the following values: $0=$ irritated, $1=$ neutral, $3=$ smile, based on the observation made by the buyer during the visit. "Final expression" takes the following values: $0=$ irritated, $1=$ neutral, $3=$ smile, based on the observation made by the buyer during the visit. "Anything offered" takes the following values: $0=$ nothing, $1=$ chair, $2=$ tea, based on the report of the buyer. "Print" is a dummy variable that takes the value of 1 if printing was done on the pen. "Location" is a dummy variable that takes the value of one for wholesalers that are not located in the main road. "Andhra trader" and "Marwari trader" are dummy variables that take the value of 1 if the wholesale dealers belong to Andhra and Marwari community, respectively. "Other trader" is a dummy variable that takes the value of 1 if the wholesaler belongs to other community (not a Marwari, Andhra, or Tamil). The omitted category is the Tamil wholesale dealers. "Andhra buyer" and "Marwari buyer" are dummy variables that take the value of 1 if the auditor belongs to Andhra and Marwari community, respectively. The omitted category is the Tamil auditors. White heteroskedasticity consistent standard errors are reported in parentheses.

***Significant at the 1 percent level.

**Significant at the 5 percent level.

*Significant at the 10 percent level.

dummy and the variables that capture the soft factors of the interaction between buyers and traders. We repeat the regressions of table 7.7 but we include whether the buyer was offered refreshment and the facial expression of the wholesaler. If the match was purely driven by having more pleasant interactions with buyers from the same community, we should see that the 
coefficient on the match variable drops when including these new variables. We find that the match variable stays virtually unchanged and the coefficients on the soft factor variables are small and not significant (unreported).

\subsubsection{Do Wholesalers of Different Ethnic Groups Differ in Wealth?}

One important concern about our findings is that the differences in bargaining behavior across ethnic groups might by driven by other underlying differences of these businesses, such as their size, their access to credit, and so forth. One could worry that our findings, for example, that Marwaris are willing to offer lower prices or less up-front payment, could be explained by other factors besides ethnicity. For instance, Marwaris could be less resource constrained and therefore able to make longer term investments in clients than other communities who might not have the same access to finance. To address the concern that the differences in contracts offered by wholesalers could primarily be a result of wealth differences across ethnic groups, we conduct several robustness checks. We conducted a survey of the wholesalers and obtained several measures that proxy for wealth levels of wholesalers, such as the size of the business or whether the wholesaler receives credit from its own distributor. Since wholesalers would not tell us in concrete numbers what their annual profit or turnover is, we asked for the shop size, the number of employees, and whether the business receives or grants credits to its own distributors.

In table 7.10, columns (1) and (2), we report the regression for final rate contracted and initial price offered including several controls for wealth level of wholesalers. We find that wholesalers who get credit from the main distributor offer lower prices. However, more importantly, we find that the effect of wholesaler ethnicity does not change when including these shop characteristics. In columns (3) and (4) of table 7.10, we repeat this regression setup but use the initial and final up-front payments as the dependent variable and regress this on the ethnicity dummies while controlling for the wholesaler characteristics. We find similar results to those reported earlier for final and initial up-front payment even after proxying for wealth levels of wholesalers. In table 7.11, we regress the shop characteristics on the ethnicity of the wholesaler. As results in column (1) and (5) show, Marwari traders have shops of smaller size and they are less likely to own shops. Thus, if anything, these results suggest that Marwari wholesalers have lower wealth levels as compared to other wholesalers. In sum, these results suggest that the differences in contracts offered by wholesalers are not driven by differences in wealth levels.

\subsection{Conclusion}

This chapter uses an audit study methodology to investigate the importance of culture in entrepreneurship. We randomly assign buyers from 


\begin{tabular}{lcccc}
\hline & Final rate & Initial rate & Final up-front & Initial up-front \\
& $(1)$ & $(2)$ & $(3)$ & $(4)$ \\
\hline Shop size & -0.074 & -0.107 & -0.008 & 0.015 \\
& $(0.054)$ & $(0.068)$ & $(0.024)$ & $(0.031)$ \\
No. of employees & 0.019 & 0.026 & -0.020 & $0.052^{*}$ \\
& $(0.055)$ & $(0.072)$ & $(0.022)$ & $(0.031)$ \\
Distributor credit & $-0.031^{*}$ & $-0.056^{* *}$ & 0.004 & 0.001 \\
& $(0.018)$ & $(0.026)$ & $(0.009)$ & $(0.012)$ \\
Offer credit & 0.016 & 0.023 & $0.021^{* *}$ & $0.034^{* * *}$ \\
& $(0.017)$ & $(0.025)$ & $(0.009)$ & $(0.011)$ \\
Own shop & -0.054 & $-0.159^{* *}$ & -0.035 & -0.021 \\
& $(0.053)$ & $(0.070)$ & $(0.024)$ & $(0.035)$ \\
Print & $0.369^{* * *}$ & $0.366^{* * *}$ & $0.246^{* * *}$ & $0.404^{* * *}$ \\
& $(0.044)$ & $(0.060)$ & $(0.019)$ & $(0.027)$ \\
Location & 0.046 & -0.008 & $-0.055^{*}$ & -0.049 \\
& $(0.113)$ & $(0.144)$ & $(0.030)$ & $(0.058)$ \\
Andhra trader & $0.208^{* *}$ & $0.253^{* *}$ & $0.130^{* * *}$ & $0.092^{*}$ \\
& $(0.094)$ & $(0.112)$ & $(0.048)$ & $(0.055)$ \\
Marwari trader & $-0.584^{* * *}$ & $-0.789^{* * *}$ & $-0.070^{* * *}$ & $-0.109^{* * *}$ \\
& $(0.044)$ & $(0.073)$ & $(0.021)$ & $(0.031)$ \\
Other trader & 0.100 & 0.207 & 0.057 & $0.090^{*}$ \\
& $(0.082)$ & $(0.127)$ & $(0.037)$ & $(0.053)$ \\
Andhra buyer & 0.058 & -0.047 & $0.067^{* * *}$ & $0.061^{* *}$ \\
& $(0.054)$ & $(0.076)$ & $(0.021)$ & $(0.031)$ \\
Marwari buyer & $-0.089^{*}$ & $-0.196^{* * *}$ & $0.070^{* * *}$ & $0.101^{* * *}$ \\
& $(0.053)$ & $(0.074)$ & $(0.024)$ & $(0.033)$ \\
Constant & $4.816^{* * *}$ & $5.560^{* * *}$ & $0.164^{* *}$ & 0.199 \\
& $(0.186)$ & $(0.250)$ & $(0.075)$ & $(0.125)$ \\
$N$ & 417 & 417 & 417 & 417 \\
$R^{2}$ & 0.356 & 0.314 & 0.329 & 0.392 \\
\hline
\end{tabular}

Notes: This table reports the results of OLS regressions. The dependent variables are "Final (contracted) rate" per pen (including printing costs if any), "Initial rate" offered per pen, "Final up-front" payment (final advance paid as a fraction of total cost), and "Initial upfront" payment (initial advance offered as a fraction of total cost). "Shop size" refers to the size of the shop. "No. of employees" refers to the number of people employed. "Distributor credit" refers to whether the wholesaler gets credit from the distributor $(1=$ no credit, $2=$ fifteen to twenty days of credit, $3=$ twenty to thirty days of credit, and $4=$ more than thirty days of credit). "Offer credit" refers to whether the wholesaler offers credit to clients $(1=$ no credit, $2=$ fifteen to twenty days of credit, $3=$ twenty to thirty days of credit, and $4=$ more than thirty days of credit). "Own shop" is a dummy that takes the value of 1 if the establishment is owned by the wholesaler. The "Print" is a dummy variable that takes the value of 1 if printing was done on the pen. "Location" is a dummy variable that takes the value of one for wholesalers that are not located in the main road. "Andhra trader" and "Marwari trader" are dummy variables that take the value of 1 if the wholesale dealers belong to Andhra and Marwari community, respectively. "Other trader" is a dummy variable that takes the value of 1 if the wholesaler belongs to other community (not a Marwari, Andhra, or Tamil). The omitted category is the Tamil wholesale dealers. "Andhra buyer" and "Marwari buyer" are dummy variables that take the value of 1 if the auditor belongs to Andhra and Marwari community, respectively. The omitted category is the Tamil auditors. White heteroskedasticity consistent standard errors are reported in parentheses.

***Significant at the 1 percent level.

**Significant at the 5 percent level.

*Significant at the 10 percent level. 
Table 7.11

Robustness

\begin{tabular}{lccccc}
\hline & $\begin{array}{c}\text { Shop size } \\
(1)\end{array}$ & $\begin{array}{c}\text { No. of } \\
\text { employees } \\
(2)\end{array}$ & $\begin{array}{c}\text { Distributor } \\
\text { credit } \\
(3)\end{array}$ & $\begin{array}{c}\text { Offer } \\
\text { credit } \\
(4)\end{array}$ & $\begin{array}{c}\text { Own shop } \\
(5)\end{array}$ \\
\hline Andhra trader & -0.063 & -0.150 & -0.224 & -0.272 & 0.040 \\
Marwari trader & $(0.183)$ & $(0.200)$ & $(0.385)$ & $(0.548)$ & $(0.184)$ \\
& $-0.299^{* *}$ & -0.200 & -0.144 & 0.044 & $-0.158^{*}$ \\
Constant & $(0.120)$ & $(0.122)$ & $(0.317)$ & $(0.294)$ & $(0.084)$ \\
& $1.777^{* * *}$ & $1.722^{* * *}$ & $2.796^{* * *}$ & $2.129^{* * *}$ & $1.245^{* * *}$ \\
$N$ & $(0.057)$ & $(0.062)$ & $(0.167)$ & $(0.170)$ & $(0.060)$ \\
$R^{2}$ & 84 & 84 & 84 & 84 & 83 \\
\hline
\end{tabular}

Notes: This table reports the results of OLS regressions. The dependent variables are "Shop size," "No. of employees," "Distributor credit," "Offer credit," and "Own shop." "Shop size" refers to the size of the shop. "No. of employees" refers to the number of people employed. "Distributor credit" refers to whether the wholesaler gets credit from the distributor $(1=$ no credit, $2=$ fifteen to twenty days of credit, $3=$ twenty to thirty days of credit, and $4=$ more than thirty days of credit). Offer credit refers to whether the wholesaler offers credit to clients $(1=$ no credit, 2 = fifteen to twenty days of credit, $3=$ twenty to thirty days of credit, and 4 = more than thirty days of credit). "Own shop" is a dummy that takes the value of 1 if the establishment is owned by the wholesaler. "Andhra trader" and "Marwari trader" are dummy variables that take the value of 1 if the wholesale dealers belong to Andhra and Marwari community, respectively. The omitted category is the Tamil wholesale dealers. White heteroskedasticity consistent standard errors are reported in parentheses. The sample only includes wholesalers who belong to Andhra, Marwari, and Tamil communities.

***Significant at the 1 percent level.

**Significant at the 5 percent level.

*Significant at the 10 percent level.

different communities to enter into contracts with wholesalers from different communities in the pen industry in India. We find that wholesalers from the Marwari community, who are considered the most entrepreneurial community, offer lower prices as compared to other communities. This seems to be a deliberate strategy by the Marwari wholesalers rather than a reflection of poor bargaining skills, since they start the negotiation with a lower price from the get-go. In the reverse direction, we also find that Marwari shoppers are offered lower prices in negotiation compared to other groups. When looking at the up-front payment that is required to initiate the contract, we again find that Marwari wholesalers are willing to accept the lowest up-front payments relative to other groups. This might be a sign that they are more trusting than other groups or are willing to take more risk on the initial customers. The results clearly suggest that ethnicity matters for the bargaining strategy and contract outcomes.

When we compare visits where the buyers and sellers are matched (or cross-matched) in terms of their community background, we find that the price offered to people of the same community is lower. However, it seems 
like this outcome is mainly driven by the Tamilians who are the dominant ethnic group in Chennai. Yet we do not find the same results for the upfront payment; that is, sellers do not demand a lower up-front payment when the shopper is from the same community. While the average level of trust in the market seems to be reasonably high (the fraction of up-front that is demanded is low), there is no evidence that the level of trust is higher between people from the same community. When we explore the soft dimensions of the negotiation; for example, how friendly shoppers are treated by wholesaler, we do not find any significant differences across entrepreneurs from different communities. These results suggest that the observed in-group favoritism is not simply driven by the fact that entrepreneurs better enjoy interactions with their own community. But rather, it seems to point toward a tacit understanding of norms about how to treat members from the same community.

\section{References}

Axelrod, R., and W. D. Hamilton. 1981. The evolution of cooperation. Science 211: 1390-96.

Ayres, I., and P. Siegelman. 1995. Race and gender discrimination in negotiation for the purchase of a new car. American Economic Review 85: 304-21.

Banerjee, A., and A. Newman. 1998. Risk bearing and the theory of income distribution. Review of Economic Studies 58 (2): 211-35.

Baumol, W. J. 2002. The free-market innovation machine: Analyzing the growth miracle of capitalism. Princeton, NJ: Princeton University Press.

Becker, G. 1998. Preferences and values. In ed. G. Becker, 3-23. Accounting for tastes, Cambridge, MA: Harvard University Press.

Bernhard, H., E. Fehr, and U. Fischbacher. 2006. Group affiliation, trust and social preferences. University of Zurich. Unpublished Manuscript.

Bertrand, M., and S. Mullainathan. 2004. Are Emily and Greg more employable than Lakisha and Jamal? A field experiment on labor market discrimination. American Economic Review 94 (4): 991-1013.

Bertrand, M., and A. Schoar. 2006. The role of family in family firms. Journal of Economic Perspectives 20 (2): 73-96.

Djankov, S., R. La Porta, F. Lopez de Silanes, and A. Shleifer. 2000. The regulation of entry. Quarterly Journal of Economics 117 (1): 1-37.

Evans, D. S., and B. Jovanovic. 1989. An estimated model of entrepreneurial choice under liquidity constraints. Journal of Political Economy 97 (4): 808-27.

Falk, A., and C. Zehnder. 2007. Discrimination and in-group favoritism in a citywide trust experiment. University of Zurich. Unpublished Manuscript.

Fershtman, C., and U. Gneezy. 2001. Discrimination in a segmented society: An experimental approach. Quarterly Journal of Economics 116 (1): 351-77.

Fukyama, F. 1996. Trust: The social virtues and the creation of prosperity. New York: Free Press.

Glaeser, E. L., D. I. Laibson, J. A. Scheinkman, and C. L. Soutter. 2000. Measuring trust. Quarterly Journal of Economics 115: 811-46. 
Gotte, L., D. Huffman, and S. Meier. 2006. The impact of group membership on cooperation and norm enforcement: Evidence using random assignment to real social groups. American Economic Review 96 (2): 212-16.

Greif, A. 1989. Reputation and coalitions in medieval trade: Evidence on the Maghribi traders. The Journal of Economic History 49 (4): 857-82.

1993. Contract enforceability and economic institutions in early trade: The Maghribi traders' coalition. American Economic Review 83 (3): 525-48.

Guha, R. 2006. India after Ghandi: The history of the world's largest democracy. New York: Ecco/HarperCollins Publishers.

Guiso, L., P. Sapienza, and L. Zingales. 2006. Does culture affect economic outcomes? The Journal of Economic Perspectives 20 (2): 23-48.

Iyer, R., and A. Schoar. 2008. The importance of hold up in contracting: Evidence from a field experiment. Working Paper.

Johnson, S., J. McMillan, and C. Woodruff. 2002. Courts and relational contracts. Journal of Law, Economics and Organization 18 (1): 221-77.

Knack, P., and S. Keefer. 1997. Does social capital have an economic payoff? A crosscountry investigation. The Quarterly Journal of Economics 112 (4): 1251-88.

Landier, A., and D. Thesmar. 2009. Contracting with optimistic entrepreneurs: Theory and evidence. Review of Financial Studies 22 (1): 117-50.

McMillan, J., and C. Woodruff. 1999. Dispute prevention without courts in Vietnam. Journal of Law, Economics, and Organization 15 (3): 637-58.

Newmark, D., R. J. Bank, and K. D. Van Nort. 1996. Sex discrimination in restaurant hiring: An audit study. The Quarterly Journal of Economics 111 (3): 915-41.

Sherif, M., O. Harvey, B. J. White, W. R. Hood, and C. Sherif. 1961. Intergroup conflict and co-operation: The robbers cave experiment. Norman, OK: University of Oklahoma.

Tajfel, H., and J. Turner. 1979. An integrative theory of intergroup conflict. In The psychology of intergroup relations, ed. W. G. Austin and S. Worchel, 335-58. Monterey, CA: Nelson-Hall.

Trivers, R. 1971. The evolution of reciprocal altruism. Quarterly Review of Biology 46 (1): 35-57.

Weber, M. 1904. The protestant ethic and the spirit of capitalism. New York: Scribner. (English translation published in UK in 1930.)

Yamagishi, T., and T. Kiyonari. 1999. The group as the container of generalized reciprocity. Social Psychology Quarterly 63 (2): 116-32. 